\title{
Study on the Stylization of Color Language in Landscape Oil Painting
}

\author{
Lihong Zhang ${ }^{1, *}$
}

\author{
${ }^{1}$ Academy of Fine Arts, Huanggang Normal University, Huanggang, Hubei 438000, China \\ *Corresponding author. Email: 352569345@qq.com
}

\begin{abstract}
As an independent genre in painting, landscape oil painting has undergone the process of breaking away from Western oil painting and forming a complete landscape color system, which is accompanied by the style evolution of color language. Taking the French Impressionism and Russian Itinerants as research object, the paper attempts to clear the development of landscape oil painting with art history as entry point in combination with style and characteristic of color language in Chinese landscape oil painting, highlighting the importance of outdoors painting for landscape color language, as well as providing relevant teaching with theory of beneficial complement and practical reference.
\end{abstract}

Keywords: oil painting landscape, color language, stylization

\section{INTRODUCTION}

As an independent type of painting, Western landscape oil painting developed through the classical, modern, and contemporary periods. At the same time, its color language style has gone through many changes. Such transformation is driven by internal factors covering the cognition process and combination of colors, as well as by external factors including social and historical background, cultural trend of thought and artist's personality. Stylization of color language represents the formation of color language style, which is a relatively stable image or symbol, and also indicator of the continuous maturity of artists or art schools. In the evolution process, stylization is inevitably swayed by the above factors, but ultimately depends on the artist's own experience. It must be noted that the style should mirror the creativity and uniqueness of the works and the creator's personality charm. Only in this way can the works enjoy artistic appeal and the value of the style be displayed.

The French Impressionism and Russian Itinerants, two artistic highlands among landscape oil painting, have wielded seminal sway on Chinese artists. At the end of the 20th century, the teaching and creation of Chinese oil paintings were in a period of wandering or self-adjustment due to the impact of postmodern art, and did not take shape until the early 21 st century. Considering the complexity of color language style of landscape oil painting and the fuzziness of its sketching teaching of in logic, this paper intends to analyze the formation of its color style from four stages.

\section{Classic SOY SAUCE COLOR}

The landscape oil paintings in classical period mainly serve as background, foiling the theme. The altarpiece The Miraculous Draft of Fishes by Swiss painter Conrad Witz is generally regarded as the earliest landscape painting. Although the practice of painting the landscape in oil paint existed in classical times, it has not been independent from the form of painting, but an accompaniment to the figures. In the 15th century, landscape that had been background for over a century finally came under limelight and won independence.

Classical landscape oil painting, whether as background or individual, takes the expression of religious and mythological connotation as the theme, with clear subjective intention. In The Jewish Cemetery by Jacob van Ruisdael, a representative of Dutch painting, the landscape is not sketched, but painted purely from imagination. The oil paintings of this period are of a dim hue, with a heavy hue of soy sauce. Although not painted from life, classical landscapes then are based on careful observation of natural scenes. This can be seen in the way the Dutch landscape painter used light. They have their own experience of life, but the light and tone of their landscapes take less account of the objective and real changes in light and color in nature. The light and color of classical landscape paintings are subjectively processed to highlight the scene. Such elaborate arrangement stems from their belief that the artistic expression of light can convey eternal and sacred power, with obvious commercial and religious purposes in essence.

The emphasis on illumination is a means of artistic expression. However, classical landscape painters 
depict their own nature in stylized colors. Influenced by inherent colors, they emphasize shape over color. In this way, color is only an auxiliary factor, and its natural attributes have not been studied, which will inevitably be replaced by later artistic styles. Therefore, Wu Guanzhong said, "ancient landscape painting is not from sketching, but conceptualized images, triggering no resonance. The truly touching landscape begins with impressionism." [1]

\section{A. Impressionist color}

The color revolution of French Impressionism marked the beginning of color independence. In the 1830 s and 1840 s, new and revolutionary changes befall in European landscape painting. Trying to express their emotions, coupled with the progress of scientists in the study of chromatics, painters have begun to refine the relationship between color and light. The color attributes, sense of light and tone are fully displayed in the picture. At this time, Barbizon School and early Impressionism made landscape painting reach peak, advocating pastoral scenery with French national characteristics, and cultivating a large number of representatives such as Miller, Corot, Rousseau, Chuck, Diaz, Dupree and Dubini.

\section{B. Opposition to classical tradition}

The reason why Parisian landscape painters went to Fontainebleau Forest for painting lies in their opposition to long-standing "historical landscape" and break the "realistic" depiction of natural images. Inspired by Dutch paintings in the 17th century and English paintings in the 19th century, they proposed to face nature for painting, believing that "scenery is not only background" and "scenery", and that nature should be the protagonist of the painting. The Barbizon artists share the weariness of urban life, the belief in "returning to nature", the realistic painting style, especially the acute control, infatuation and prominence of light and shadow. It is no exaggeration that without Barbizon there would be no real landscape painting. Landscape paintings of this period play a role of connecting the past and the future.

Based on the Barbizon school, the Impressionists showed a distinct artistic personality. Their life-oriented art creation further get rid of the dependence on history, myth and religion as well as the bondage of traditional painting program of storytelling. They walk out of the studio and into nature, leaving on the canvas the instantaneous changes in temperature of nature, making it an eternal image. Compared with classical landscape paintings, Impressionism completed a leap between landscape schema and color style.

\section{Fascination with light}

Landscape paintings by painters from the Barbizon school to the Impressionism and Post-impressionism are imbued with a love of light. As a pioneer of impressionism, Corot Camille took that landscape painting should be "nature-oriented and sketched from life". In contrast to the past when painters painted the dark part of the scene, he made the dark part transparent and bright, thus greatly increasing the brightness of the whole picture and showing the effect of air and light. Influenced by predecessors and absorbing the research results of natural scientists on light, impressionist painters fully showed the color changes of objects in their sketches, reflecting the influence of the surrounding environment under light on the color of objects. The practice of light and shadow by Monet, "the leader of Impressionism", changed the relationship between shadow and contour line. The boundary between the two was vague and implicit, making light and shadow integrated. Monet was fascinated by the sunlight on the walls of the church, which sparkled with color as it atomized. It is Monet's unique light and shadow processing method that makes his works very distinctive. In the post-Impressionist period, painter Vincent Van Gogh even tried to show the flaming sunlight in his paintings, which turned the region's vineyards into a golden yellow that was set against the purple.

\section{Pursuit of natural tones}

The knowledge of natural tones comes from the diligent practice of Impressionism. The basic theory and technique basis of color in modern color teaching system appeared in Impressionism landscape oil painting. Color language covering color property, environment color, hue, and chroma, etc., are presented intuitively. Impressionist's use of color is subtle and seeks to exhaust natural tones, as reflected in Monet's Hay Stack, and it is no exaggeration to say that he created tones that were impossible even for nature. Such expression of color expands the research spectrum of chromology, returns to the essential attribute of color, breaks the old habit of classical soy sauce covering the picture, and abandons the "ideal landscape painting", which has been popular in France for nearly two hundred years.

In short, Impressionism opened up a civilized virgin territory for art history. Whether landscape image thinking, or color language logic, Impressionism broke through the shackles of that era by the way of superficial thinking, so that it is difficult for the world to follow the rhythm of such color thinking. Impressionists' free temperament and painting style deeply influenced Chinese painters studying in France in the early 20th century. The color in impressionist landscape paintings is passionate and even rampant. The brushstrokes of light and color are randomly dyed, 
while the objectivity and truth of form are ignored. Impressionists take conditional color as the basis, emphasizing color over shape, and modelling becomes the auxiliary factor of color.

\section{MONUMENTAL SHAPE COLOR}

"Unlike the Impressionists, the landscape painters of Russian Itinerants did not confine themselves to the pursuit of light and color, but emphasized more on the generalization and shaping of forms." ${ }^{1}$ After the 1860s, influenced by Russian democratic aesthetics, French realism and Barbizon school, a group of Russian painters broke away from the academic tradition of monographs on myths and Bible themes. They went out of the studio to observe and draw from nature, and set up Russian Itinerants to create independent landscape paintings with Russian characteristics.

\section{A. Rigorous color painting procedures and shape shaping}

As for landscape oil painting creation, rigorous and scientific body shaping is the typical difference between Russian Itinerants and French Impressionism. The Impressionists paid little attention to form, sometimes distorting its structure, exaggerating and dismembering its color. Painters represented by Levitan completed the sketching or creation procedure of the oil painting landscape, believing that landscape painting is easy to be contained by the scenery, so they should take the initiative to control the scenery instead of copying it, and learn to block surface segmentation to cover moving position. Attention should be paid to the differences in the size, weight and temperature of objects. Before starting landscape sketching, one should draw sketches, or even complete sketches. One should also carefully compose pictures to study the image segmentation of color blocks, draw color drafts and do color-limited exercises. The interlocking traces of Levitan's painting at various stages can be seen in his work. In particular, the color block decomposition of the small color draft reflects the painter's judgment and understanding of light and tone. Once the small color draft is established, the production of large landscape painting can be assured.

The color modeling of landscape painting is represented by Shishkin and Levitan. The representative works of Shishkin, known as the "forest singer", include Wood Forest (1872), Morning in a Pine Forest (1889), etc., in which the Russian forest is

Color theory comes from the book On the Coordination between the Law of Simultaneous Contrast of Color and the Inherent Color of Objects by Parisian chemist Chevreul (1786-1889) in 1839. The book laid the scientific foundations of Impressionism and NeoImpressionism, providing the impressionists with new basic models through the study of sunlight, which alters the natural color of natural objects, and light in the atmosphere of a landscape. tall as monument. The trees were carefully shaped and painted in realistic colors, trying to follow the original look of the objects, just like portraits of pine forests. Levitan's masterpiece covers Birch Forest (1889), Spring · High Water (1897), etc. Though not painting Russian forests in the way Shishkin did, Levitan paints unremarkable rural landscapes. However, his works strive to truly reproduce the shape and color of nature, and create a comprehensive and meaningful image of Russian nature with monumental composition and simple color language that highly summarize the natural scenery.

\section{B. Inheriting Impressionism's use of light}

Russian Itinerants painters inherited the French Impressionism style. In 1873, Ilya Yafimovich Repin went on a three-year study tour in France, while Monet exhibited Impression Sunrise in 1874. That is to say, Repin was just in time for the exhibition, where he learned their small strokes depicting ever-changing sunshine. Valentin Alexandrovich Serov was also influenced by Impressionism's techniques for painting light and colors. His famous work, Young Girl with a Peach (1888), is featured with impressionist Pleinairism. Russian landscape painters are fascinated with sunlight. Levitan was acutely aware that only the sun could change the hue of landscape, and the greatest force in sketching came from the sun. The beauty of Russia's dark natural landscape lies in the dazzling and penetrating sun. He also took that the sun and black were incompatible. Rather than pigment, black deadens pigment. It's therefore no wonder that Levitan decided to remove the dark tones from his picture. In order to obtain inspiration and subject from nature, the artist traveled to the outskirts of Moscow and the Volga River, sketching everywhere, looking for his own scenery and sunshine.

\section{The pursuit of grey tones}

Grey tones were more common in the works of painters from Soviet school. Painters after Russian Itinerants, especially during the Soviet period, hold that "the tone in the picture should serve the theme, and the color what the sketch is to express." [3] The techniques employed by both the Impressionism and the Soviet one attempted to finish one hue at a time, that of grey. "The grey advocated by Impressionism is based on natural color and studies the natural properties of color, while that of Soviet Union and Russia is mostly explained by humanistic principles and restricted by sketches or even illustrations." [4] Thus, strictly speaking, the tone of Impressionism is tonal, while that of the Soviet Union is grey. The former is colored gray, while the latter is gray. The gray used by the Soviet school prefer three primary colors on average, which were harmonized by them. Such gray can make the finish of picture better, which can be reflected on scenery, figure, making color 
more implicative and charming. Therefore, it is highly respected by Chinese oil painters.

\section{IMAGERY COLOR}

Imagery color is new direction for the expression of landscape oil painting, as well as a unique feature of its pro-language color style. Modern and contemporary Chinese artists seeking breakthroughs in art have begun the upsurge of studying in the West. In the late 19th and early 20th centuries, Chinese artists went to Japan, Italy and France for study. In the first half of the 20th century, a large number of Chinese artists studied in the Soviet Union. This hugely swayed Chinese oil painting, especially landscape painting.

\section{A. Influence of Impressionism and Soviet school}

The content has been adjusted for the convenience of writing. First, the study in the Soviet Union aims to pursue realistic art in line with the demands of then China. China from 1949 to 1957 witnessed the vigorous vitality of realistic art, which is inseparable from learning from Russia: the Soviet Union. At that time, students were sent to study in the Soviet Union, and crash oil painting training courses by Soviet painters were also conducted to develop relevant painting skills and emphasize the reflection of art on real life. Works then are literary and narrative. However, landscape oil paintings then were only copy-cat, still struggling.

The stay in France is driven by Impressionism. Yan Wenliang, a veteran oil painter, had an early in-depth study of Impressionism. He studied in France in 1928, influenced by classicism and Impressionism. His paintings are rigorous in structure and life-like. He highlights the changes of external light and color. Many of his works combine realism, light and color. The painters under the wing of Impressionism during their stay in France cover Lin Fengmian, Wei Tianlin, Liu Haisu and $\mathrm{Wu}$ Guanzhong. Liu Haisu, one of them, "likes impressionism in particular. $\mathrm{He}$ found that Western art later tended to be more subjective, which coincides Chinese painting's emphasis on freehand brushwork." [5] Influenced by printed materials, people hold that Impressionism was opposed to realism from the 1920s and 1930s to the early 1970s and 1980s. Wu Guanzhong inherited the concept of Impressionism and realized his aesthetic pursuit with his unique works, namely, "comments on the formal beauty in sketching and the transformation of oil painting language in Chinese beauty". [6]

\section{B. Writing and image}

Writing and image are typical of traditional Chinese aesthetic concepts. Writing serves as a way of artistic presentation, and contemporary Chinese landscape oil painting enjoys a tendency of writing or freehand brushwork. "The painting emphasizes "writing" and expression of personal feelings, pursuing the traces of color language. The carrier adopted is an 'image'." [7] Liu Xie, a scholar of the Liang Dynasty, mentioned in The Literary Mind and the Carving of Dragons that "image" grows out of artistic conception. Only when it is generated, can it be employed as basis to show the charm of works of art. The "Xiang" in the image (Yi $\mathrm{Xiang}$ ) is purely objective. Though growing out of the thing, it is different from the thing. The emotion caked in "image" is "Yi". Only when the two are unified, can complete aesthetic value be obtained. The 21 st century saw a new landscape in the development of Chinese landscape oil painting. The color trace of landscape oil painting in different places presents the typical writing style, while the color language of the scenery pursues image between similarity and difference. Wang Keju, a representative landscape painter, said in an exhibition that landscape oil paintings in recent years were all about landscape. These works are no longer merely sketching practice, let alone the representation of natural scenery, but exploration of language transformation and emotion expression in the face of nature. Instead of relying on narrative representation of emotions, the picture has paid more attention to visual factors and emotion expression. The pursuit of combining writing trace with the charm of freehand brushwork in Chinese landscape oil painting, to some extent, enhances its color language and provides a good paradigm for its teaching and creation.

\section{CONCluSION}

Art goes through the process of inheritance and breakthrough, and art history is no exception. The exploration of color language of landscape oil painting is also a process of relentless learning from masters. Such saying is also mirrored in Cai Yuanpei's Painting, "learning Western painting should start from copying". The available color language illustrations provided by predecessors are followed by artistic practice, namely outdoor sketching and creation. Nowadays, landscape sketching in art practice seems to be easy and common. However, when painting becomes a way of education and Images as Hostorical Evidence becomes a special task, its artistry will be greatly reduced. There was a period when the painting of landscape could not be carried out normally and was forced to do secretively. [8], which seems to be the fate that Impressionism cannot escape. Like Van Gogh's work, real art survives time. Conceptual and technical rules aside, outdoor sketching obviously helps to refine color language. Although there are camera viewfinder for references inside, seeing the world with one's own eyes will endow the world different meaning. 


\section{References}

[1] Wu Guanzhong. Combination of Oil Painting Landscape and Chinese Landscape Painting [J]. Art. 1999(7): 65-66. Jia Mingyu. Work Collection of Wu Guanzhong [M]. Wenhui Press. 1998: 92. (in Chinese)

[2] Qi Da, Huo Xingguang. Masterpieces of the West:-Color Landscape [M]. Shanghai: China Academy of Art Press. 2017(3):8. (in Chinese)

[3] Liu Yi, Situ Yong. Oil Painting Techniques (Revised Edition) [M]. Beijing: People's Fine Arts Publishing House. 2016(9): 149. (in Chinese)

[4] Liu Yi, Situ Yong. Oil Painting Techniques (Revised Edition) [M]. Beijing: People's Fine Arts Publishing House. 2016(9): 150. (in Chinese)

[5] Chinese Oilpainting in the 20th Century [M]. Beijing: Beijing Publishing House, Beijing Art Photography Publishing House. 2001(8): 8. (in Chinese)

[6] China Artists Association. Scene of Time: The National Observational Works Collection [M]. Beijing: People's Fine Arts Publishing House. 2013(11): 20. (in Chinese)

[7] Zhu Liyuan. The Unity of Heaven and Man [M]. Shanghai: Fudan University Press. 1998: 98. (in Chinese)

[8] China Artists Association. Scene of Time: The National Observational Works Collection [M]. Beijing: People's Fine Arts Publishing House. 2013(11): 5. (in Chinese) 